\title{
DESAFIOS E POTENCIALIDADES DO ESTÁGIO CURRICULAR SUPERVISIONADO DO CURSO INTERDISCIPLINAR EM EDUCAÇÃO DO CAMPO DE CIÊNCIAS DA NATUREZA
}

\author{
Viviane de Almeida Lima* \\ Milene Ferreira Milleto** \\ José Vicente Lima Robaina ${ }^{* *}$
}

\begin{abstract}
Resumo: Os cursos de Licenciatura em Educação do Campo da área de Ciências da Natureza trazem como um de seus desafios a necessidade de se discutir a formação de professores por área de conhecimento, não para atuar no campo, mas para atuar na Educação do Campo, em que se considere os princípios, especificidades e demandas emergentes desse contexto. Ante a essa perspectiva, o presente trabalho objetivou identificar os desafios e potencialidades para a prática da interdisciplinaridade no Estágio Curricular Supervisionado III, do Curso Interdisciplinar em Educação do Campo: Ciências da Natureza - Licenciatura, da Universidade Federal da Fronteira Sul (UFFS), Campus Erechim. O Estágio III oferece aos educandos a experiência de conhecer diversas organizações educativas do campo e/ou urbanas, realizando observações em instituições de ensino médio, além de trabalhar uma oficina temática interdisciplinar com os alunos desse grau na escola do campo. Para tanto, utilizou-se do método da pesquisa qualitativa e documental, procedendo-se à análise de relatórios do Estágios III. Como resultados, pode-se inferir que ocorrem lacunas e dificuldades para a efetivação de práticas interdisciplinares, dentre essas, especialmente as relacionadas a estrutura curricular fragmentada das escolas e a dificuldade de planejamento coletivo das atividades interdisciplinares. Porém, emergem elementos potencialmente ricos oriundos do processo formativo na Licenciatura em Educação do Campo com habilitação em Ciências da Natureza, destacando-se a aceitação por parte dos alunos de práticas interdisciplinares.
\end{abstract}

Palavras-chave: Formação de professores. Práticas interdisciplinares. Educação do Campo.

\footnotetext{
* Professora da Universidade Federal da Fronteira Sul do Curso Interdisciplinar em Educação do Campo Ciências da Natureza -Licenciatura - Campus Erechim. Doutoranda do Programa de Pós-Graduação em Educação em Ciências: Química da Vida e Saúde; Universidade Federal do Rio Grande do Sul, Porto Alegre, RS; Endereço eletrônico: viviane.lima@uffs.edu.br

** Professora da Escola Estadual de Ensino Médio Nossa Senhora da Assunção. Doutoranda do Programa de Pós-Graduação em Educação em Ciências: Química da Vida e Saúde; Universidade Federal do Rio Grande do Sul, Porto Alegre, RS; Endereço eletrônico: mmiletto@hotmail.com

*** Professor da Universidade Federal do Rio Grande do Sul do Curso do Curso Educação do Campo Habilitação em Ciências da Natureza. Orientador do Programa de Pós-Graduação em Educação em Ciências: Química da Vida e Saúde; Universidade Federal do Rio Grande do Sul, Porto Alegre, RS; Endereço eletrônico: jose.robaina@ufrgs.br
} 


\section{Introdução}

A trajetória histórica da Educação do Campo no Brasil mostra que as políticas educacionais brasileiras, na sua grande maioria, não contemplavam e nem priorizavam as necessidades e a realidade dos povos do campo. Desta maneira, a Educação do Campo começa a fazer parte das discussões nacionais através da I e II Conferência Nacional por uma Educação Básica do Campo, realizadas em 1998 e 2004. Nessas, instituições e movimentos sociais defendiam o direito dos povos do campo às políticas públicas de educação, apontando ações para a escola do campo com o objetivo de compreender que o povo tem o direito de estudar no lugar onde vive, sobrevive, mora e trabalha (ALENCAR, 2010). Esses eventos deixaram como legado uma Declaração Final "Por uma Política Pública de Educação do Campo", em que se estabeleceu a necessidade de uma educação de qualidade e que valorizasse a formação inicial e em exercício dos docentes educadores do campo.

Diante dessa perspectiva é essencial que a formação de educadores do campo privilegie a compreensão da educação como prática política e social, para atuarem nos espaços educativos (escolares e não escolares) que valorizem a vida, a cultura do sujeito no ${ }^{2} \mathrm{e}$ do $^{3}$ campo. A formação de professores do campo, assim compreendida, possibilita fortalecer a construção de um ensino significativo, partindo da realidade da comunidade, valorizando sua diversidade social e cultural e, ainda, enriquecendo-se e desenvolvendo-se, essencialmente, pela prática interdisciplinar.

Nessa direção, os cursos de Educação do Campo surgem com a demanda de formar professores para a docência nos anos finais do ensino fundamental, no ensino médio das escolas das áreas rurais e, ainda, atuar na gestão com a finalidade de superar as desvantagens históricas sofridas pelas populações do campo. No entanto, na contramão do entrelaçamento disciplinar, evidencia-se essa formação com estratégias metodológicas baseadas em áreas do conhecimento, sendo: Linguagens; Ciências da Natureza e Matemática; Ciências Humanas e Sociais; e, ainda, Ciências Agrárias (BRASIL, 2009).

No caminho para concretizar a necessária formação interdisciplinar e que leve em consideração um educador que não apenas atue no campo, mas que mobilize conhecimentos a partir da especificidade e demandas do campo, é que emergem lacunas diversas. Fazenda (2008), argumenta que a formação de professores é um dos principais obstáculos à efetivação da interdisciplinaridade, salientando que será preciso mudar a relação pedagógica

\footnotetext{
${ }^{1}$ Disponível em https://www.revistas.ufg.br/interacao/article/download/1418/1432

2 No: o povo tem direito a ser educado no lugar onde vive (CALDART, 2011, p.149).

${ }^{3}$ Do: o povo tem direito a uma educação pensada desde o seu lugar e com a sua participação, vinculada à sua cultura e às suas necessidades humanas e sociais (CALDART, 2011, p.150).
} 


\section{\#tear}

fundamentada na transmissão do conhecimento, para uma relação dialógica em que todos os saberes são igualmente importantes, requerendo, para tanto, interação e parceria entre os docentes.

No mesmo sentido, Imbernón (2004) afirma que a formação inicial de professores deveria promover experiências interdisciplinares que lhe permitisse integrar os conhecimentos e os procedimentos das diversas disciplinas (ou disciplina) com uma visão psicopedagógica. Para o autor, esse direcionamento deveria ocorrer desde sua formação inicial e, posteriormente, em sua atuação pedagógica.

Compreende-se, assim, a importância da interdisciplinaridade e seus aspectos lacunares nos contextos de formação de educadores no e do campo. Ademais, evidencia-se que as investigações ainda são incipientes quando se fala dos cursos interdisciplinares de formação inicial de docentes, que surgiram nos últimos anos e carecem de aprofundamento teórico e metodológico.

Nesse sentido, o presente artigo é fruto de uma investigação que teve como objetivo identificar os desafios e as potencialidades vivenciados no Estágio III de um Curso Interdisciplinar em Educação do Campo em Ciências da Natureza - Licenciatura, da Universidade Federal da Fronteira Sul (UFFS), Campus Erechim.

\section{Caminhos metodológicos}

Para Fazenda, Tavares e Godoy (2015), a pesquisa qualitativa permite observar hábitos de ação, confrontar a realidade, compreender intersubjetividades e, além de outros pontos, ampliar a capacidade de "ver" e "ouvir" do pesquisador. A pesquisa documental, por sua vez, constitui-se de uma fonte natural e poderosa de informações, permitindo a retirada de evidências que fundamentem afirmações e declarações do pesquisador (LÜDKE, ANDRÉ, 1986). Diante dessas possibilidades, a pesquisa qualitativa documental foi o caminho metodológico escolhido para o percurso dessa investigação.

Os documentos, no presente estudo, se constituíram dos relatórios do componente "Pesquisa e Prática no Ensino Médio - Estágio III" do Curso Interdisciplinar em Educação do Campo em Ciências da Natureza da UFFS, do Campus de Erechim, construídos no segundo semestre de 2017.

A escolha do Estágio III se deu pelo fato que nesse, além de conhecer o campo de estágio, através de observações, os alunos-estagiários devem realizar uma oficina interdisciplinar de Ciências da Natureza (que envolvam conceitos de Biologia, Química e Física) para o ensino médio. Os relatórios trazem a contextualização da escola, uma 


\section{\#tear}

fundamentação teórica sobre o ensino de Ciências para o Ensino Médio, os planos de aulas e uma reflexão sobre o desenvolvimento da atividade em sala de aula. Ainda, a descrição das atividades realizadas na oficina, bem como uma reflexão crítica sobre a elaboração e execução da atividade com potencialidades e dificuldades sobre o trabalho desenvolvido como futuros docentes.

Para a coleta das informações/dados realizou-se uma leitura aprofundada dos referidos relatórios e, posteriormente, a sistematização dos dados dentro de dois campos conceituais desafios e potencialidades, utilizando-se da técnica de análise de conteúdo, que possibilita interpretar os materiais textuais.

De acordo com Bardin (2010), a análise de conteúdo "é um conjunto de técnicas de análise das comunicações que utiliza procedimentos sistemáticos e objetivos de descrição do conteúdo das mensagens", possibilitando assim "a interferência de conhecimentos relativos às condições de produção (ou, eventualmente, de recepção), interferência esta que recorre a indicadores (quantitativos ou não)" (BARDIN, 2010, p. 38).

\section{O estágio curricular supervisionado na Licenciatura em Educação do Campo}

O estágio curricular supervisionado do Curso Interdisciplinar em Educação do Campo - Ciências da Natureza da UFFS se caracteriza pelas "possibilidades de experimentação da docência na área na qual o futuro professor está buscando sua formação" (BRASIL, 2013, p. 58) e compreende um total de 405 horas do curso. Inicia-se a partir da $5^{\mathrm{a}}$ fase, se constituindo dos seguintes componentes curriculares, a saber: Pesquisa e Prática Pedagógica no Ensino Fundamental (Estágio I), Estágio Supervisionado no Ensino Fundamental (Estágio II), Pesquisa e Prática Pedagógica no Ensino Médio (Estágio III) e Estágio Supervisionado no Ensino Médio (Estágio IV).

Os Estágios I e III têm como objetivo conhecer o campo de estágio onde futuramente irão atuar, por ocasião do estágio curricular de regência (Estágio II e IV). Assim, os Estágios I e III possibilitam um mapeamento por parte dos estagiários no que tange à "leitura do contexto escolar, envolvendo a realidade sociocultural, a instituição, a docência, o currículo, os sujeitos e a contextualização, envolvendo o mapeamento e a problematização das questões que emergem do espaço campo de estágio" (BRASIL, 2013, p. 60).

A intervenção do discente estagiário diretamente em sala de aula acontece no componente curricular Estágio Supervisionado no Ensino Fundamental (Estágio II) e no Estágio Supervisionado no Ensino Médio (Estágio IV), em que é desenvolvido o processo didático-pedagógico em uma classe. Os estágios de regência possibilitam aos alunos entrar em 


\section{\#tear}

contato com a realidade da escola e da profissão docente, além de poderem compartilhar experiências e saberes com professores que já são regentes de turmas há mais tempo.

Todos os componentes curriculares de Estágios Supervisionados têm como prática ser ministrado por três professores-formadores que constituem a área de Ciências da Natureza do Curso de Educação do Campo. Os docentes da área de Ciências da Natureza têm formação inicial em Química, Física ou Biologia e se atentam a orientar as atividades e o planejamento do estágio supervisionado na perspectiva de práticas interdisciplinares em Ciências da Natureza.

O Estagiário Supervisionado III se organiza através de oficinas interdisciplinares a partir de temáticas que emergem do contexto local e que se possibilite envolver os conteúdos do ensino de Biologia, de Química e de Física de maneira a promover a superação da fragmentação do conhecimento. Por conseguinte, os professores-formadores contribuem a partir de seu arcabouço conceitual de sua formação específica para a construção de atividades que envolvam os conceitos da área de Ciências da Natureza de maneira interdisciplinar.

Os professores supervisores das escolas são escolhidos pelos alunos-estagiários ou indicado pela própria escola. Os supervisores são os responsáveis pelas disciplinas de Ciências e com formação inicial em Ciências Biológica, no caso dos Estágios I e III. No ensino médio a área de Ciências da Natureza, são divididas em disciplinas de Química, Física e Biologia em que os professores que ministram tem a formação inicial na área específica. $O$ que impacta muito no estágio da área de Ciências da Natureza, visto que os professores supervisores direcionam os conteúdos de acordo com sua disciplina forçando muitas vezes os alunos-estagiários trabalhem quase disciplinarmente.

\section{A Pesquisa e Prática Pedagógica no Ensino Médio (Estágio III)}

Mesmo considerando a primazia de todos os momentos de estágio curricular, a presente pesquisa deteve-se na realização do Estágio III, no qual além das observações da realidade escolar, os discentes desenvolvem uma oficina temática interdisciplinar, de quatro horas, com o acompanhamento dos docentes responsáveis pelas disciplinas do Domínio Conexo $^{4}$ (Fundamentos da Educação, Didática Geral, Língua Brasileira de Sinais, Política

\footnotetext{
${ }^{4}$ [...] conjunto de disciplinas que se situam em espaço de interface de vários cursos, sem, no, no entanto, poderem ser caracterizadas como exclusivas de um ou de outro. No caso do curso Interdisciplinar em Educação do Campo - Ciências da Natureza - Licenciatura, o Domínio Conexo compõe-se de um conjunto de disciplinas da área pedagógica, as quais têm por finalidade situar e habilitar o acadêmico do curso para a prática docente na área de formação prevista (Ciências da Natureza) (BRASIL, 2013, p. 50)
} 


\section{\#tear}

Educacional e Legislação do Ensino no Brasil e Teorias da Aprendizagem e do Desenvolvimento Humano) e os da área de Ensino de Ciências (Biologia, Física e Química).

Os relatórios de estágio advindos das observações do contexto e das compreensões da oficina constituem-se os documentos de análise para a presente pesquisa e sua leitura e análise permitiram a categorização dos dados em duas grandes frentes: a) desafios e b) possibilidade da prática da interdisciplinaridade no Estágio Curricular Supervisionado III, do Curso Interdisciplinar em Educação do Campo: Ciências da Natureza - Licenciatura, da UFFS, Campus Erechim.

\subsection{Desafios de práticas interdisciplinares no ensino médio}

Um dos grandes desafios apontados pelas estagiárias na elaboração das oficinas interdisciplinares para o ensino médio é a estrutura curricular fragmentada nas escolas de educação básica, em que na grande maioria cada disciplina da área de Ciências da Natureza é ministrada por docentes com formação inicial específicas. Esses docentes com formação em química ou física ou biologia realizam as atividades em separado de acordo com sua formação não trabalhando em nenhum momento a área de Ciências da Natureza na perspectiva da interdisciplinaridade.

De igual modo, a orientação na escola se dá exclusivamente, por um docente supervisor com formação específica, indicado pela escola e não por um grupo de professores que constituam a área de Ciências da Natureza, o que dificulta a construção e discussão de um trabalho interdisciplinar.

Essa dificuldade também perpassa ao âmbito dos professores-formadores na orientação de práticas e/ou ações interdisciplinares, visto que a maioria “[...] dos docentes que atuam na educação superior são oriundos de processos formativos extremamente fragmentados, com pouco ou quase nenhum diálogo entre as disciplinas de uma mesma área em sua própria formação”. (MOLINA, 2014, p. 14).

Diante dessa lacuna, o Curso Interdisciplinar em Educação do Campo: Ciências da Natureza - Licenciatura, da UFFS busca minimizar a problemática através de um esforço por parte dos professores-formadores da área de Ciências da Natureza (Química, Física e Biologia) em trabalhar conjuntamente nos componentes curriculares de estágios. Esse é um dos principais desafios do Curso, conforme apontado no Projeto Político, que refere ser necessário o seu enfrentamento. 


\section{\#tear}

Apesar de enredado nas fronteiras das disciplinas que dão sustentação teóricometodológica, as áreas representadas no curso, com o foco em Ciências da Natureza, por suas diferentes especificidades, deverão criar espaços e tempos para desenvolver propostas de intervenção pedagógica na perspectiva da interdisciplinaridade, concretizando na prática a atitude interdisciplinar na escola do campo. (BRASIL, 2013, p.30)

Percebeu-se por parte das estagiárias uma certa dificuldade em planejar atividades interdisciplinares que articulassem os conceitos da área de Ciências da Natureza (Química, Física e Biologia). No enfrentamento desse obstáculo, pode-se assinar duas constatações relevantes. A primeira, refere-se ao fato que as professoras supervisoras da escola atribui às estagiária conteúdos ligados à sua disciplina específica, não permitindo que se perca a sequência de aulas que vinha ministrando e, nem mesmo, que sejam trabalhados conteúdos de outros bimestres do ano, conforme relato da estagiária " o referido estágio foi realizado com base no conteúdo em que a professora regente repassou e que faltava ainda trabalhar neste trimestre do ano letivo".(Relatório A, 2017, p.22)

A segunda constatação refere-se à insegurança dos professores titulares em planejar atividades interdisciplinares, especialmente para o ensino médio. Essa questão pode ser verificada, especialmente, no seguinte trecho do relatório: “Os alunos e professores já estão acostumados a trabalhar por área de ensino [...] ninguém quer mudar o jeito que estão acostumados, pois esta nova modalidade requer tempo para seu planejamento "(Relatório B, 2017, p. 17),

\subsection{Potencialidades das práticas interdisciplinares}

Como potencialidades percebidas nas análises de conteúdo dos relatórios pode-se citar a aceitação por parte dos alunos do ensino médio. Tal percepção ocorreu quando da realização de uma oficina interdisciplinar de Ciências da Natureza, onde observaram um grande envolvimento em sala de aula, conforme relata as Estagiárias A e B

\footnotetext{
[...] os alunos gostaram tanto da metodologia adotada que queriam participar mais e mais e meu tempo era curto"(Relatório B, 2017, p. 24).

"Os alunos realizaram as atividades com muita responsabilidade e fizeram muito bem feitos, isto demonstrou muito interesse pelo assunto e a forma diferente de trabalhar em sala de aula. (Relatório A, 2017, p. 23).
}

Outra potencialidade que se pode citar em relação ao desenvolvimento das oficinas e, portanto, à prática interdisciplinar, é a abordagem temática, que vai ao encontro do Parâmetros Curriculares Nacionais (PCN'S). Esses tratam do trabalho interdisciplinar como uma proposta que visa minimizar o ensino fragmentado, descontextualizado e 


\section{\#tear}

compartimentalizado, apontando para o "desenvolvimento do currículo de forma orgânica, superando a organização por disciplinas estanques e revigorando a integração e articulação dos conhecimentos, num processo permanente de interdisciplinaridade" (BRASIL, 2000, p.17). Nessa direção, as estagiárias buscaram utilizar uma metodologia em que houvesse, tanto a participação do professor quanto do aluno em sala de aula.

Dessa forma, utilizaram-se dos três momentos pedagógicos (DELIZOICOV, ANGOTTI, PERNAMBUCO, 2002) como tentativa de inovar o processo de ensinar na direção de uma prática interdisciplinar: 1) a problematização inicial, em que trabalharam com situações reais que os alunos conheciam, desafiando-os a expor criticamente suas opiniões; 2) a organização do conhecimento, momento em que o professor organiza os conhecimentos necessários para compreensão da problematização; e, por fim, 3) a aplicação do conhecimento momento que o aluno sistematiza o conhecimento a fim de entender as situações iniciais

\section{Considerações finais}

A análise dos relatórios de Estágio III, apresentados pelas alunas do Curso Interdisciplinar em Educação do Campo, em Ciências da Natureza da UFFS, do Campus Erechim, possibilitou compreender as dificuldades, bem como as potencialidades, vivenciadas na elaboração de práticas interdisciplinares, nesse processo formativo.

Como dificuldades para os processos de ensino-aprendizagem interdisciplinares em nível de ensino médio, identificou-se, especialmente, a tradicional e enraizada estrutura curricular fragmentada típica das escolas de educação básica, ainda, a formação dos professores formadores nesses moldes e, também, a dificuldade no planejamento das atividades interdisciplinares. Em outro sentido, as potencialidades identificadas para a concretude de práticas pedagógicas interdisciplinares referem-se à aceitação dos alunos e a consonância com o previsto nos PCNs.

Ante ao exposto, percebe-se que o desafio posto para essa formação interdisciplinar desses sujeitos que estão preparando-se para a docência em escolas do/no campo, perpassa pelo âmbito da universidade chegando até as estruturas curriculares das escolas. Nessas, devese promover a organização de novos espaços que articulem diferentes componentes disciplinares, antes isolados e fragmentados, em uma estrutura que propicie o diálogo dos componentes entre si, e especialmente, a relação desses com a realidade local, dando sentido ao conhecimento.

Entende-se, assim, que a formação interdisciplinar em Ciências da Natureza no Curso de Educação do Campo se mostra como um desafio tanto para os estagiários quanto para os 


\title{
\#tear
}

professores-formadores desse curso. Essa formação, de certa forma, rompe com o ensino tradicional e específico que se tem nos cursos de licenciatura, privilegiando uma única área do saber ou cada uma isoladamente.

Como professores-formadores dessas estagiárias que serão os futuros professores, tem-se por certo a necessidade de se continuar na busca de estratégias para a efetivação dessas práticas e ações interdisciplinares. Isso, tanto nas atividades e propostas interdisciplinares das áreas de conhecimento quanto nas nossas próprias práticas docentes valorizando as partes e todo dos processos pedagógicos de ensinar e aprender, de modo especial, na Educação do e no campo.

\section{CHALLENGES AND POTENTIALITIES OF SUPERVISED CURRICULAR INTERNSHIP IN THE INTERDISCIPLINAR COURSE IN NATURAL SCIENCES IN RURAL EDUCATION}

\begin{abstract}
BSc University courses in Natural Sciences in Rural Education bring as one of their challenges the need to discuss teacher education in different fields, not to work in rural areas, but to work in Rural Education, where the principles, specialties and demands that come from this context are considered. Considering this perspective, the aim of this study was to identify the challenges and potentialities for the interdisciplinary practice in the Supervised Curricular Internship III, of Rural Education Interdisciplinary Course: Natural Sciences BSc, Universidade Federal da Fronteira Sul (UFFS), Campus Erechim. The Internship III offers to students the opportunity to meet several rural and urban learning institutions, to observe high school institutions, and to work an interdisciplinary workshop with their students in the rural school. This study consisted of a qualitative research and document research, where the reports from Internship II were analysed. The results showed that there are gaps and difficulties for interdisciplinary practice effectiveness, especially the ones related to a fragmented curriculum in the schools and the difficulty of collective planning of interdisciplinary practices. Nevertheless, there are potentially rich elements that come along the process of becoming BSc in Rural Education BA with qualification in Natural Sciences, especially the acceptance of interdisciplinary practice by students.
\end{abstract}

Keywords: Teachers Education, Interdisciplinary Practice, Rural Education.

\section{Referências}

ALENCAR, M. F. dos S. Educação do campo e a Formação de Professores: construção de uma política educacional para o campo Brasileiro. Ci. \& Tróp., Recife, v.34, n. 2, p.207-226, 2010.

BARDIN, L. Análise de Conteúdo. Lisboa: Edições 70, 2010.

BRASIL. Ministério da Educação. Universidade Federal da Fronteira Sul. Pró-Reitoria de Graduação. Diretoria de Organização Pedagógica. Projeto Pedagógico do Curso 


\title{
\#tear
}

Interdisciplinar em Educação do Campo - Ciências da Natureza - Licenciatura. Erechim: 2013.

\author{
2000. \\ Parâmetros Curriculares Nacionais Ensino Médio: bases legais. Brasília: MEC,
}

. Ministério da Educação. Secretaria de Educação Continuada, Alfabetização e

Diversidade - Secad. Edital de Convocação no 09, de 29 de abril de 2009. Brasília: 2009.

CALDART, Roseli Salete. Por uma Educação do Campo: traços de uma identidade em construção. In: ARROYO, Miguel Gonzalez; CALDART, Roseli Salete; MOLINA, Castagna (organizadores). Por uma Educação do Campo. 5.ed. Petrópolis, RJ: Vozes, 2011.

DELIZOICOV, Demétrio; ANGOTTI, José André; PERNAMBUCO, Marta Maria. Ensino de Ciências: fundamentos e métodos. São Paulo: Cortez, 2002.

FOLLADOR, Eliane Fátima Halabura. Degradação Ambiental. 2017.50f. Relatório de Pesquisa e Prática Pedagógica no Ensino Médio - Estágio III - Universidade Federal da Fronteira Sul, Erechim, 2017.

FAZENDA, Ivani (org.). O que é interdisciplinaridade? São Paulo: Cortez, 2008.

Interdisciplinaridade: história, teoria e pesquisa. 5. ed. Campinas, SP: Papirus, 2012.

FAZENDA, I.; TAVARES, D.; GODOY, H. Interdisciplinaridade na pesquisa científica.

Campinas, São Paulo: Papirus, 2015.

OLIVEIRA, Grasiele da Conceição. Saneamento Básico. 2017.36f. Relatório de Pesquisa e Prática Pedagógica no Ensino Médio - Estágio III - Universidade Federal da Fronteira Sul, Erechim, 2017.

IMBERNÓN, F. Formação docente e profissional: formar-se para a mudança e a incerteza. 4.ed. São Paulo, Cortez, 2004.

LÜDKE, Menga e ANDRÉ, Marli E. D. A. Pesquisa em educação: abordagens qualitativas. São Paulo: EPU, 1986.

MOLINA, M.C.(org). Licenciaturas em Educação do Campo e o ensino de Ciências da Naturais: desafios à promoção do trabalho docente interdisciplinar. Brasília: MDA, 2014.

MELLO, Josiane Loureiro. Como vivem as pessoas que possuem a Síndrome de Down. 2017.38f. Relatório de Pesquisa e Prática Pedagógica no Ensino Médio - Estágio III Universidade Federal da Fronteira Sul, Erechim, 2017.

SEGHETTO, Maiara. Relatório de Estágio III. 2017.66f. Relatório de Pesquisa e Prática Pedagógica no Ensino Médio - Estágio III - Universidade Federal da Fronteira Sul, Erechim, 2017. 